水文・承资源学会誌

J. Japan Soc. Hydrol. \& Water Resour.

Vol. 10, No. 3(1997) pp. 248-258

\title{
Development of Software for the Broader Application of WEFAX Data
}

\author{
WEFAXデータの有効利用のためのソフトウェア開発
}

\author{
Md. Aminul Karim CHOWDHURY* \\ チョードリ アミヌル カリモ \\ Hitoshi NISHIMURA $^{* *} \cdot$ Hiroyoshi SHI-IGAI** \\ 西村仁嗣・椎貝博美
}

WEFAX is the image signal transmitted from the Geostationary Meteorological Satellite (GMS). There are some commercially available programs to receive the signals and process them by means of the personal computers. All of the available programs are of almost similar level of working facilities for image preparation of specific hours, preparation of animated images from a series of images, detection of cloud top temperature, etc. As GMS is launched by Japan, it has been widely used in Japan for various purposes. On the other hand, some problems may arise if you make use of it for other countries. For example, the images of dislocated areas are deformed due to the earth curvature, which creates misinterpretation of clouds for those regions. The second difficulty is that the image data are overlapped by the latitudinal, longitudinal, and coastal lines, which may lead to erroneous result for digital data analyses. In order to improve these points, a series of new software is developed.

Key words: GMS, WEFAX, Geometric correction, Affine transformation

WEFAXは，静止気象衛星(GMS)功配伯された画像信号である. パソコンによりそれを受后しかつ処理するために，すてにい くつかのソフトウェアが開発されている，それらのソフトウェアは，ある時刻における画像作成，動画像の作成，雲の温度の同定な どにおいて, ほとんど同様の機能をもっている.GMSは, 日本においてきまさまな目的で幅広く利用されているが, 他の国々に対し て利用しようとすると,いくつかの問題が生じる. 例兄ば，画像の周辺部に位置する国々は，地球の曲率により変形して写っており， このことはその領域における雲量の俱った把暒につながる. 第二の問題は, 画像上に緯線, 経線, 海岸線などが引かれていることて あり,それらはデー夕解析を行う際, 諟った結果を运く原因となる。これらの問題点を改良するために, 一連の新しいツフトウェア の開発を行った。

キーワード : GMS, WEFAX, Geometric correction, Affine変換

\section{I . INTRODUCTION}

WEFAX is the name of a image signal transmitted from the Geostationary Meteorological Satellite (GMS) in every hour a day. In brief, the whole earth hemisphere is scanned first by GMS and those scanned images are sent to the Meteorological Satellite Center, Japan, where the lines of latitude, longitude, coast, etc., mentioned as extra lines in this paper, are

\footnotetext{
*Doctoral program in Engineering, University of Tsukuba, Japan. e-mail: chow@ surface.kz.tsukuba .ac.jp 筑波大学大学院

**Institute of Engineering Mechanics, University of Tsukuba, 305 Japan

筑波大学椣造工学係 $=305$ つくば市天王台1-1-1
} 
superimposed to that scanned imagery for the general visualization. This modified imagery is sent back to the satellite, and again transmitted as WEFAX image signal to the users. The signals are received by a receiving system, and a probable cloud formation, cloud movements, cloud top temperature, and some other information can also be known from these images.

GMS data is extensively utilized in Japan for meteorological and other remote sensing purposes. The importance of GMS is increasing day by day not only in Japan but also in other countries as well. Recently, the project of GAME, (GEWEX Asian Monsoon Experiment) has been launched to determine the characteristics of the monsoon and understand the feedback processes involved in the monsoon system, particularly in radiation, clouds and land surface hydrology, associated with its interseasonal, seasonal and interannual variability. As a part of this experiment, GMS will be used for Asia and Australia. As GMS is launched by Japan, it is widely used in Japan for various aspects. However, some problems may arise if we use it for other countries. They are:

(1) The satellite is located on the equator at $140^{\circ}$ East, so that the imageries received by the satellite are not much deformed near that location. The images are more and more deformed at the areas apart from that location. The deformation of the earth imagery is caused by the earth curvature, and some image corrections are needed to improve the deformed imagery.

(2) The intensity of the pixels on the latitudinal, longitudinal and coastal lines of an imagery are changed from its original intensity by the Meteorological Satellite Center, Japan, to show those lines clearly in it. This must also be corrected.

It is already mentioned that there is some commercially available software to receive and produce the WEFAX signal, and all of the software have almost the similar level of working facilities. However, these software cannot overcome the problems described before. Therefore, a set of programs have been developed to improve the situation. The technique as the key tool of this software is to detect an image pixel from it's geographic coordinates. For this purpose, some geometric correction techniques (Cracknell et al., 1989) of satellite imageries are reviewed and referred to. The GMS itself may incline with respect to the original axes and may drift from its original position. The information of the inclinations and drifts of the satellite during the scan, which is known as the attitudes of the satellite, is necessary to detect a pixel from its latitudinal/longitudinal coordinates. Since the commercially available software cannot provide this information, some geometric correction techniques of satellite imageries are needed. This is the basic idea of the newly developed software.

\section{I . FEATURES OF THE SOFTWARE AVAILABLE IN THE MARKET}

The WEFAX signal can be received by various available commercial systems. Two systems, Hakuyo system (7) and Kenwood system (6) have been tested in our laboratory. These two systems are of similar performance and have the same working facilities, mainly regarding with 1) preparation of cloud images from WEFAX data of specific hours of a specific day, 2) preparation of animated images for specific periods, 3) determination of cloud top temperature of a specific pixel and 4) determination of cloud height of a specific region. The signals received by any of the systems described before are converted to six bits binary form, and stored as WEFAX image data. Each image consists of 800 lines, where each line contains 800 pixels, and each pixel consists of the combination of six bits of binary. The intensity of a pixel depends upon the data format, and this data format is different from one system to the other unfortunately. The data format of Hakuyo system is shown in Fig. 1(a), where the intensity of a pixel is the result of combina- 


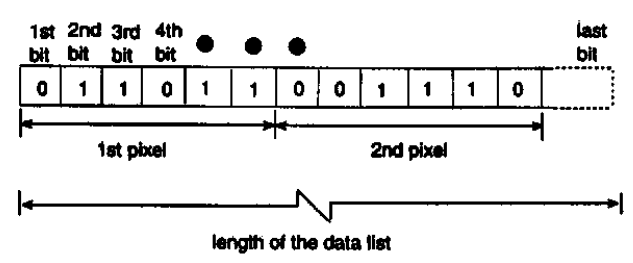

(a)

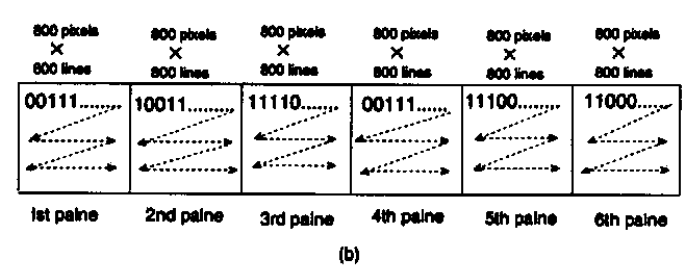

Fig. 1 (a): Data fomat of Hakuyo system, (b): Data fomat of Kenwood system

tion of six successive bits. For example, if the arrangement of binary is like 011011001110100 , then the intensity of the first pixel is 27

$$
\left(0 \times 2^{5}+1 \times 2^{4}+1 \times 2^{3}+0 \times 2^{2}+1 \times 2^{1}+1 \times 2^{0}\right)
$$

and the second pixel is 14

$\left(0 \times 2^{5}+0 \times 2^{4}+1 \times 2^{3}+1 \times 2^{2}+1 \times 2^{1}+0 \times 2^{0}\right)$.

The data format is different in case of Kenwood system. Fig. 1(b) shows the format of this type of data arrangement. As shown in Fig. 1(b), there are six planes, and every plane consists of $800 \times 800$ bits of data, and the intensity of one pixel also consists of the combined intensity of six bits; extracting one bit from each plane. For example, if the binary arrangement in each plane is like as Fig. 1(b), then the intensity of first pixel is 27

$$
\begin{aligned}
& \left(0^{1 \mathrm{P}} \times 2^{5}+1^{2 \mathrm{P}} \times 2^{4}+1^{3 \mathrm{P}} \times 2^{3}+0^{4 \mathrm{P}} \times 2^{2}+1^{5 \mathrm{P}} \times 2^{1}+\right. \\
& \left.1^{6 \mathrm{P}} \times 2^{0}\right),
\end{aligned}
$$

second pixel is 14

$$
\begin{aligned}
& \left(0^{1 \mathrm{P}} \times 2^{5}+0^{2 \mathrm{P}} \times 2^{4}+1^{3 \mathrm{P}} \times 2^{3}+1^{4 \mathrm{P}} \times 2^{2}+1^{5 \mathrm{P}} \times 2^{1}+\right. \\
& \left.0^{6 \mathrm{P}} \times 2^{0}\right),
\end{aligned}
$$

and so on, where superscript "nP" means the plane number.

\section{METHODOLOGY}

\section{The basic idea of the developed software}

The main objectives of this study are to make the orthogonal imagery from the deformed imagery for the proper visualization of the cloud, and to eliminate the extra lines, for example, latitudinal, longitudinal, and coastal lines from the original imagery and add those lines again after the orthogonal image is formed. For this purpose, it is necessary to find out a tool which detects the image pixel corresponding to the geographic coordinates, i.e., latitudinal/longitudinal coordinates, since the commercially available software lacks of this facilities. For this purpose, the satellite attitudes, such as inclinations and altitude of the satellite during the earth scan, should be kept under consideration. Since there is no header file included in the WEFAX data referring to the satellite attitudes, a certain technique of the geometric correction of images must be utilized. Extensive work has been done on the geometric correction of LANDSAT data, for example, Bachmann et al., 1992; Chang et al., 1995; Ho et al., 1986; and Emery et al., 1989. The correction requires a technique that processes image to transform latitudinal/longitudinal coordinates to image coordinates.

Basically there are two methods for geocorrection according to the previous works (Cracknell et al., 1989):

1. Regression analysis using a set of well distributed ground control points (GCP) consist. ing of Affine transformation between distorted and geocorrected image.

2. Geographic location by using orbital parameters of the satellite, i.e., Geographic coordinates of any pixel from orbital and trigonometric equations.

Applying the first method, the newly developed technique evaluates the satellite inclinations and altitude during the earth scan.

The outline of the technique is briefly explained as follows:

1) Fig. 2(a) presents a WEFAX imagery of the globe without the coastal lines. Suppose we are concerning about the region $X$, the partial imagery corresponding to the region $\mathrm{X}$ has been produced, which is Fig. 2(b) .

2) Let A, B, C, and D be the distinct intersec- 


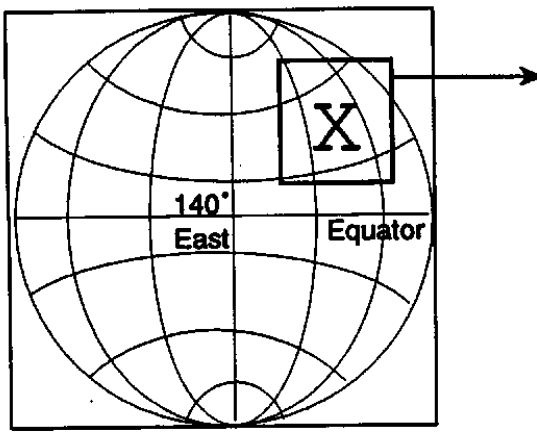

(a)

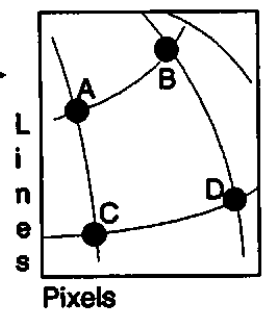

(b)

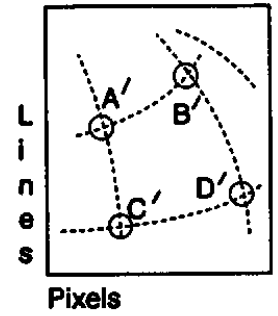

(c)

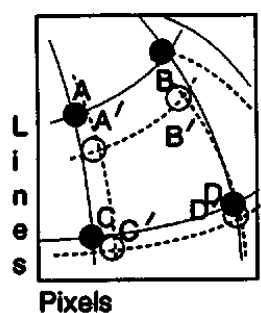

(d)

Fig. 2 Technique of determining the inclinations and altitude of the satellite during the earth scan from the imagery. (a): A WEFAX image of the globe. (b): Partial imagery produced from the globe imagery for the region $\mathrm{X} . \mathrm{A}, \mathrm{B}, \mathrm{C}$, and $\mathrm{D}$ are the distict intersections of the latitudinal and longitudinal lines belong to that imagery. (c): Position of A, B, C, and D in the same image frame if there is no satellite disturbance. (d) Superimposition of (c) on (b).

tion points of the latitudinal and longitudinal lines. These points may be manually selected on the computer, and their corresponding image coordinates (lines/pixels) and geographic coordinates (latitudes/longitudes) are known.

3 ) An earth-satellite relation is shown in Fig.

3. It is considered that the satellite may be inclined along $x, y$, and $z$ axis by disturbances during the earth scan. If there is no disturbance, other parameters, such as the radius of the earth, altitude of the satellite $(35,800$ $\mathrm{km}$ from the earth surface), and location of the satellite $\left(140^{\circ}\right.$ East on the equator), must be considered. By using a set of trigonometric equations and the fixed parameters described before, image coordinates of any geographical location can be computed. By this technique, the image coordinates of $A, B, C$, and $D$ of Fig. 2(b) can be computed to $A^{\prime}, B^{\prime}$, $\mathrm{C}^{\prime}$, and $\mathrm{D}^{\prime}$ for Fig. 2(c). Note that the geographic coordinates of $\mathrm{A}, \mathrm{B}, \mathrm{C}$, and $\mathrm{D}$ are same as $A^{\prime}, B^{\prime}, C^{\prime}$, and $D^{\prime}$, but corresponding image coordinates are different.

4) Fig. 2(d) is the superposition of Fig. 2(c) on Fig. 2(b). Here, $\mathrm{A}^{\prime}, \mathrm{B}^{\prime}, \mathrm{C}^{\prime}$, and $\mathrm{D}^{\prime}$ are the computed positions of $\mathrm{A}, \mathrm{B}, \mathrm{C}$, and $\mathrm{D}$ when there is no disturbance. A reverse computational technique is then applied and the

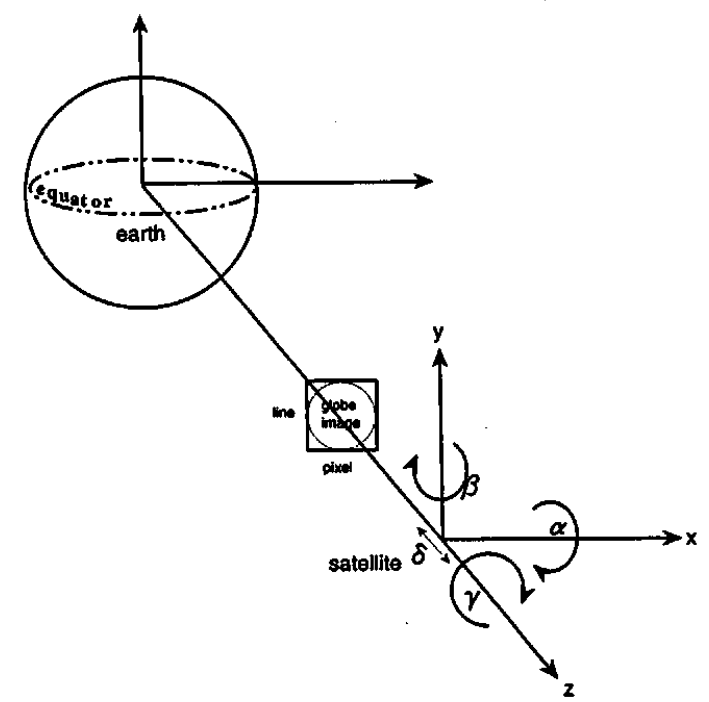

Fig. 3 The Earth-Satellite coordinate system. It is considered that the satellite can be inclined along $\mathrm{x}, \mathrm{y}$ and $\mathrm{z}$ axes with the value of $\alpha, \beta$ and $\gamma$ respectively, and can be shifted to or from the earth with the value of $\delta$.

necessary inclinations and altitude of the satellite are calculated to match $\mathrm{A}^{\prime}, \mathrm{B}^{\prime}, \mathrm{C}^{\prime}$, and $\mathrm{D}^{\prime}$ to $\mathrm{A}, \mathrm{B}, \mathrm{C}$, and $\mathrm{D}$. The obtained information of the inclinations and the altitude of the satellite is commonly expressed as the "attitudes of the satellite", and this will be used 


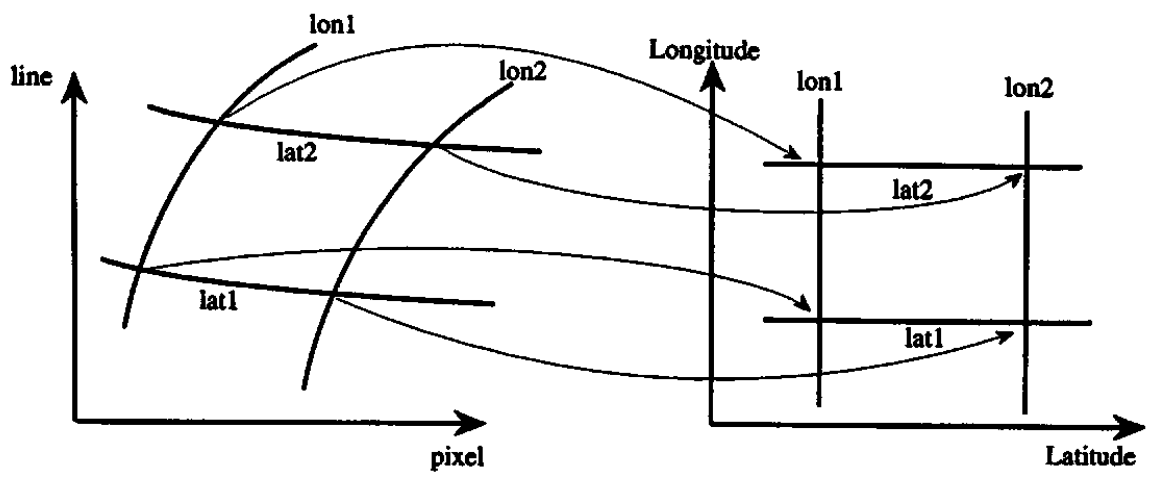

(a)

(b)

Fig. 4 (a): image frame of the deformed imagery, (b): image frame of the orthogonal imagery

as the coefficients of the computation for the further operation.

\section{Technique of the elimination of extra lines from the imagery}

The presence of extra lines in a WEFAX imagery causes misinformation on the lines. The basic technique to eliminate extra lines is to detect pixels which are associated with the extra lines on the imagery and then to interpolate the pixels with the surrounding pixel intensities. The operational steps are explained as follows.

Step-1: Pick up specific data of a region of interest from the WEFAX image data to prepare a partial imagery. For example, if the region is $\mathrm{X}$ of Fig. 2(a), the line and pixel number of the left bottom corner of the squire $\mathrm{X}$ will work as a reference point to create partial imagery from the whole imagery.

Step-2: An automatic procedure is developed to compute the probable satellite disturbances from the partial imagery. The procedure is already explained in sec III (1).

Step-3: Using the earth-satellite relation (Fig. 3) and the probable satellite disturbances, the position of pixels on the extra line are detected.

Step-4: Intensity of a detected pixel is estimated through interpolation in the reference of the surrounding pixels, which eliminates the extra lines from the imagery.

\section{3 . Technique of orthogonal image forma- tion from the deformed earth imagery}

The first two steps of the extra line elimination process are the basic operation to prepare orthogonal imageries. After these two steps, geographical patterns on the global surface must be mapped on a flat plane (Fig. 4(a and b)). The concerning region is geographically extended from longitude-1 (lon1) to longitude-2 (lon2) and from latitude-1 (lat1) to latitude-2 (lat2) as is shown in Fig. 4(a). By using the earth-satellite relation, the pixels on lat1 can be specified together with the pixel intensities. These pixels will be placed horizontally on the flat image frame (Fig. 4(b)), and thus the curved line latl is converted to a straight line on the flat image. The repetition of this procedure will form a flat image without much difficulty.

\section{IV . PROGRAM INSTALLATION AND OPERATION}

A series of programs have been developed to conduct the procedures mentioned above. These programs mainly consist of two source files, IMG.BAS and IMG.C. These are linked by a batch file named as IMG_X.BAT. 
NEC 98 series computer is suitable for this operation, since Hakuyo and Kenwood are using this series as standard. Assuming the developed programs are to be installed in drive $B$. The directories must be formed under this drive as is explained in Fig. 5. Note that Quick Basic and Quick $\mathbf{C}$ compilers are necessary. Some file editor is comfortable for this operation. A commercial file editor named MIFES is used in this study.

The developed program IMG.BAS and IMG.C, and the batch file IMG_X.BAT should be installed under the IMAGE directory. DATA directory should remain under the image directory, and it contains coastal line data named COAST.DAT, and border line data or CONTRY.DAT, and WEFAX data should remain directly under $\mathrm{B}$ drive.

The outline of the operational work is schematically explained in Fig. 6. Note the following explanations.

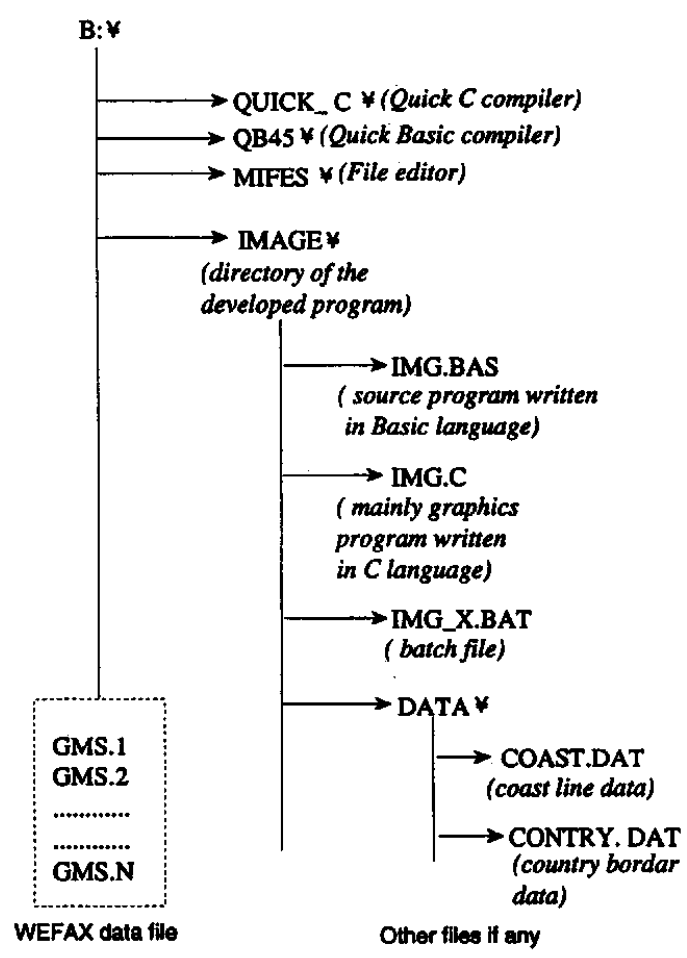

Fig. 5 Structure of the directories and files arrangement
1) Install the program IMG.BAS, IMG.C, IMG_X.BAT, and the QUICK BASIC and QUICK $\mathrm{C}$ compilers under the directories as described in Fig. 5.

2) "Copy" or "move" the WEFAX data to drive B. MS-DOS command may be used for this purpose. The copied data file should be renamed as GMS. ${ }^{* *}$ where ${ }^{* *}$ can be any number.

3 ) Get the menu-1 as described in Fig. 6 . Choose $\mathbf{0}, \mathbf{1}$, or $\mathrm{C}$ on necessity.

4) Press $\mathbf{Q}$ and $\mathbf{X}$ successively to compile and make an execution file.

5) Press $=$ to get the menu-2 which is to select the area of interest. At this stage, data of a given region can be picked up for modification. These regions are referred to Bangladesh, Malaysia, Thailand, and Vietnam respectively.

6) Assume that you chose Bangladesh, then press $\mathbf{B}$ to pick up the data of the region of Bangladesh, and the menu-3 will be reached.

7 ) Follow the operational steps as described in Fig. 6 for any other modification works.

\section{SAMPLE APPLICATION}

Four imageries are presented in this paper to demonstrate the newly developed software. A WEFAX infra-red (IR) data is chosen from the archived data. As a test imagery, Bangladesh is chosen for the partial representation of the imagery. The area of this imagery covers from $70^{\circ}$ to $100^{\circ}$ East in longitude and from $20^{\circ}$ to $35^{\circ}$ North in latitude as is seen in Fig. 7 (a).

Fig. 7(b) shows the modified partial imagery, where the latitudinal, longitudinal, and coastal lines are eliminated and replaced by the interpolated gradation values. Fig. 7 (b) may be compared with the Fig. 7 (a). Note that the extra lines are eliminated.

Fig. 7 (c) is the modification of Fig. $7(\mathbf{b})$, where country border lines of India, Bangladesh, Nepal, Bhutan, and Burma and the coastal line of the Bay-of-Bengal are inserted for a better visualization of that region. 


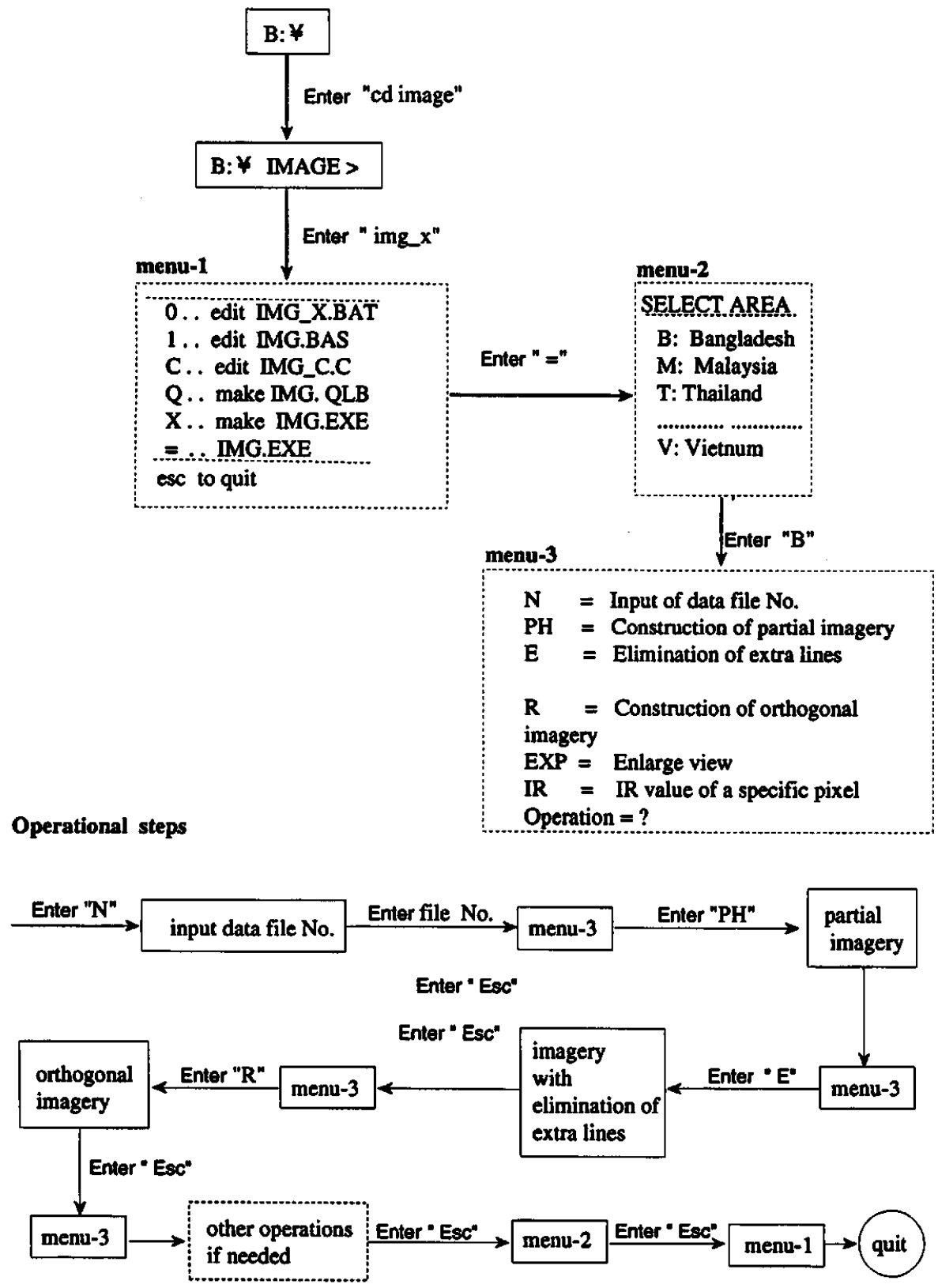

Fig. 6 Flow of the operational steps

Fig. $7(d)$ is the orthogonal representation of Fig. 7 (c). If you like, the orthogonal imagery may be produced without imposing the extra lines. The orthogonal imagery can also be produced directly from Fig. 7(a) or Fig. 7(b) and the extra lines can be imposed later on that orthogonal imagery, which will produce the better picture.

\section{VERIFICATION OF THE RESULTS}

In order to verify the elimination process of extra lines, histograms of IR values are made for the four cross-sections of Fig. 8(a) and Fig. $8(\mathbf{b})$ respectively. Fig. $8(a)$ is the partial 


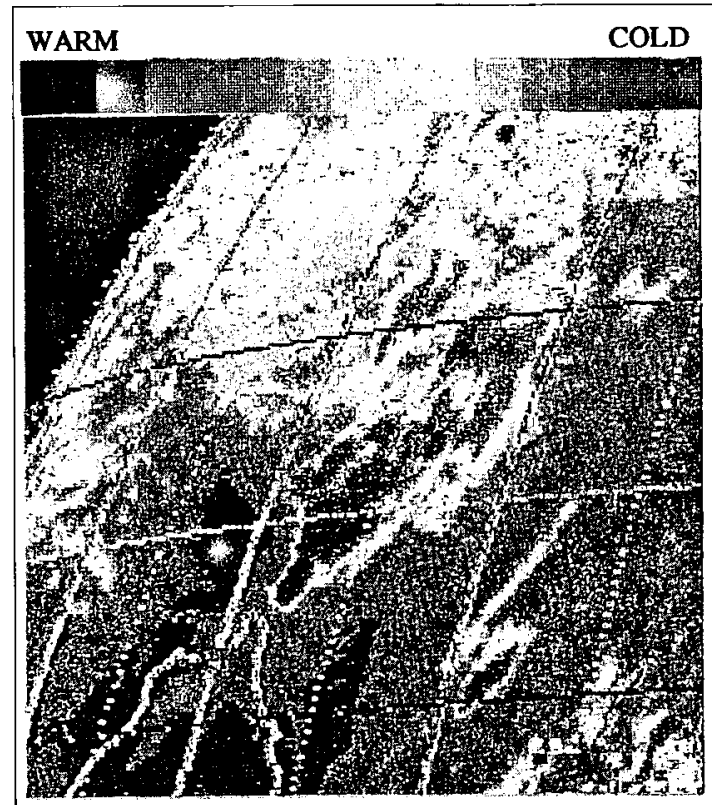

(a)

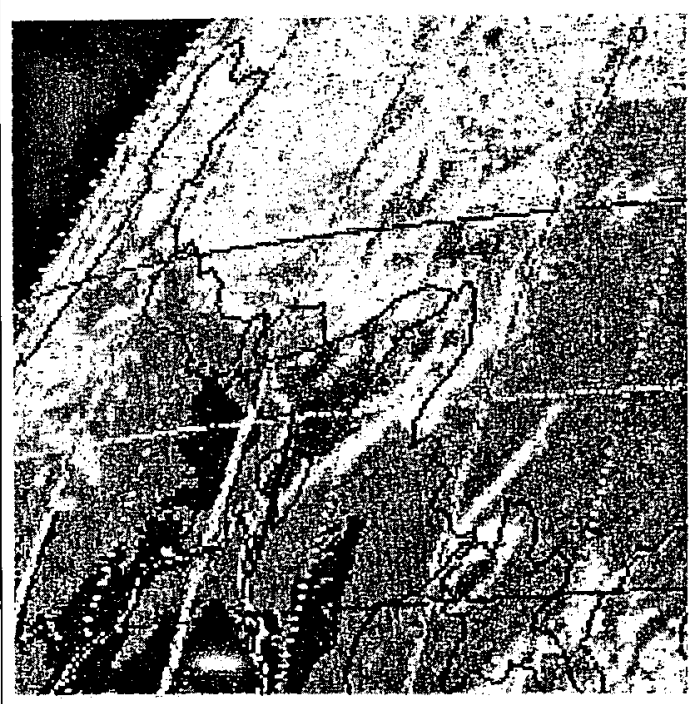

(c)

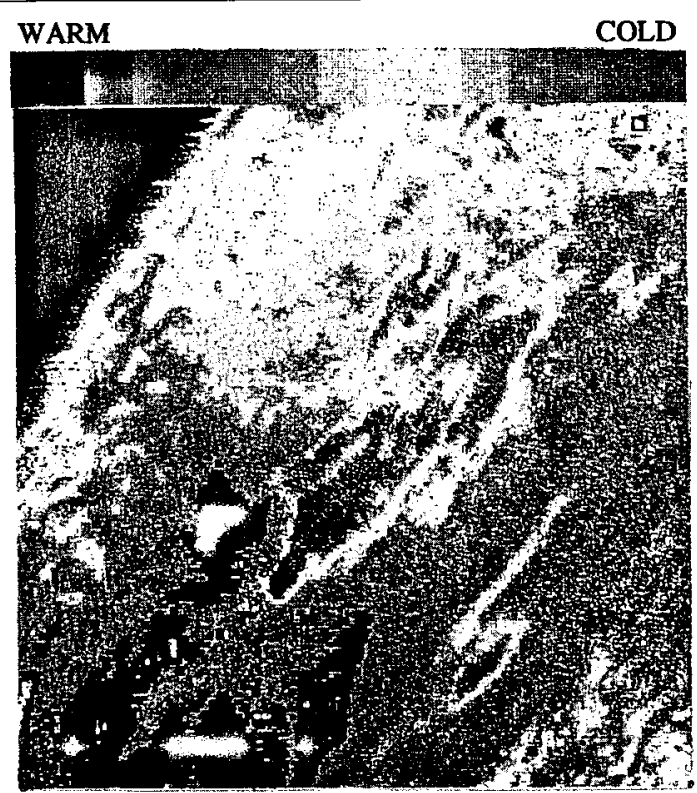

(b)

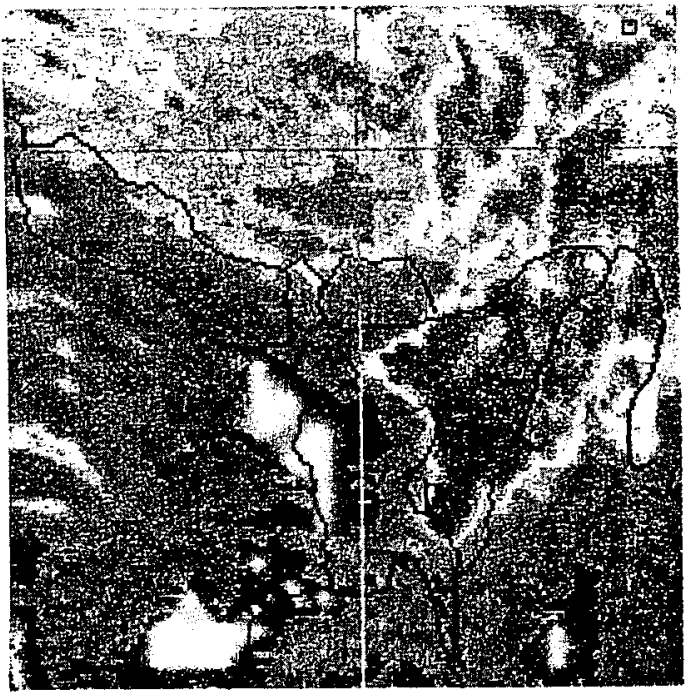

(d)

Fig. 7 (a): partial imagery produced from the original WEFAX data, (b): Imagery reproduced after eliminating the latitudinal, longitudinal and coastal lines from the partial imagery, (c): Imagery reproduced after inserting the country lines (India, Bangladesh, Nepal, Bhutan, and Burma) into the partial imagery, (d): Orthogonal imagery reproduced from the deformed WEFAX imagery 


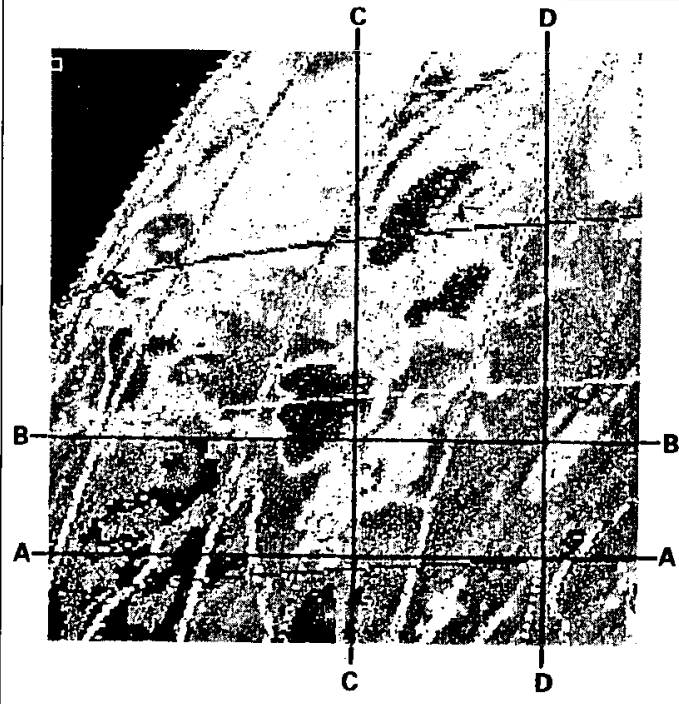

(a)

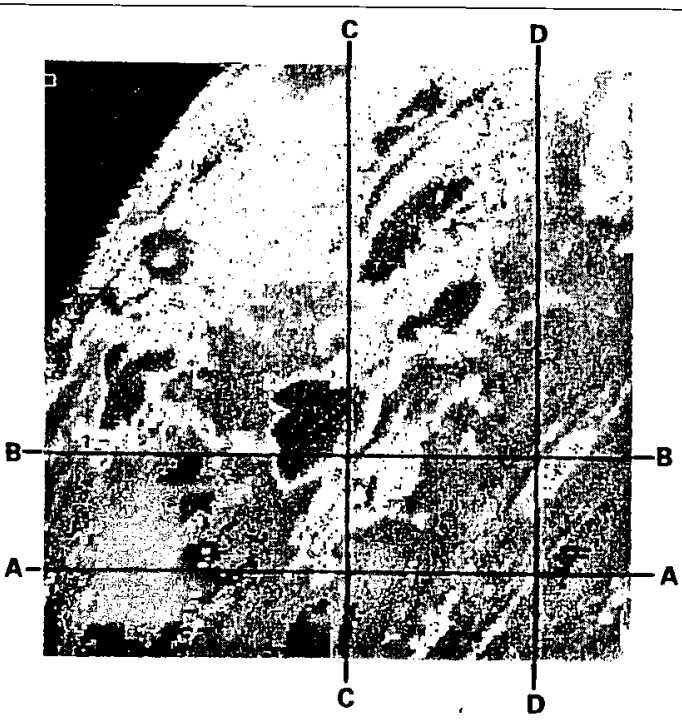

(b)

Fig. 8 (a): Imagery before eliminating the extra lines, (b): Imagery after eliminating the extra lines

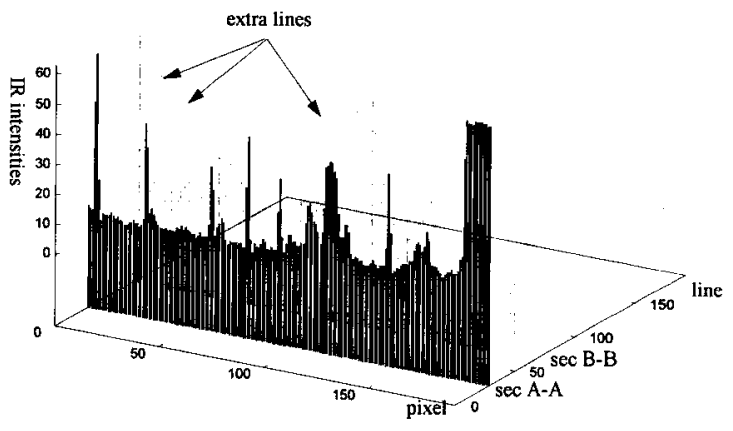

(a)

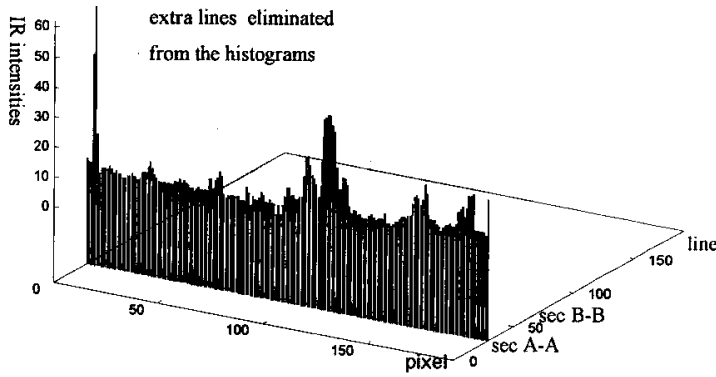

(b)

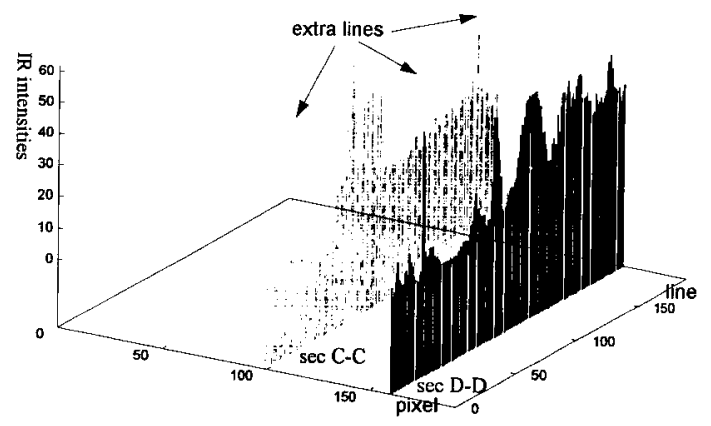

(c)

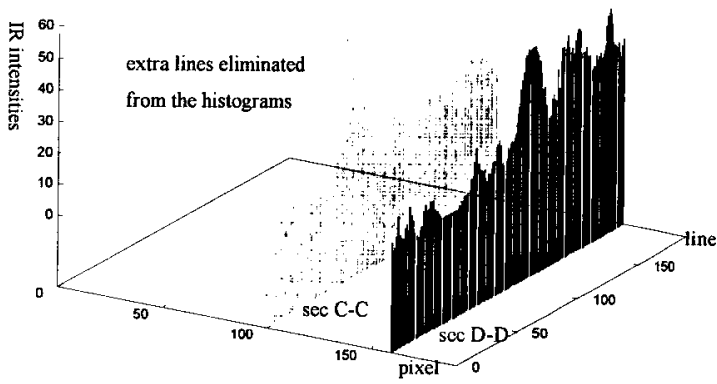

(d)

Fig. 9 (a): Histograms of IR intensities at section $A-A$ and $B-B$ before the elimination of extra lines, (b): Histograms of IR intensities at section A-A and B-B after the elimination extra lines, (c): Histograms of IR intensities at sections $C-C$ and $D-D$ before the elimination of extra lines, (d): Histograms of IR intensities at sections C-C and D-D after the elimination extra lines 
imagery constructed from the original data, and the elimination process of latitudinal, longitudinal and coastal lines is carried out on this imagery. Fig. 8(b) presents that modified imagery. Four cross-sections (section A-A, B$B, C-C, D-D)$ are taken at the same position for the two imageries. Fig. 9(a) and Fig. 9(c) represent the histograms before the elimination process and Fig. 9(b) and Fig. 9(d) represent the histograms after the elimination. Some scattered elongated lines are visible in Fig. 9(a) and Fig. $9(\mathbf{c})$, which is due to the presence of extra lines. By the elimination process, these extra lines are detected and replaced by the estimated intensities. These smooth histograms of Fig. 9(b) and Fig. 9(d) prove that the latitudinal, longitudinal and coastal lines elimi. nation process works effectively and properly. The image (Fig. 8(b)) as well as the histograms prove that the modified IR data after the elimination of extra lines can be used for further research works like the original IR data.

\section{CONCLUSION}

A procedure of converting the WEFAX imagery is presented in this study. The various aspects of the software developed on the basis of this procedure are also described. Although Bangladesh, Malaysia, Thailand and Vietnam have been used as the test regions in this paper, this software can be used for any other regions covered by GMS.

WEFAX imagery is easily available, and needs very simple and economical instrumental set-up to receive the signal. Since WEFAX signal can be received in any region covered by the GMS free of charge, the use of this software in addition to the existing ones may create a broader usage of GMS for scientists and engineers.

By this process, a partial binary data file which covers the region of interest is constructed first from the original WEFAX data, and various analytical techniques are carried out by means of this data. One original WEFAX data file needs 0.48 megabytes of disk space, whereas the partial data file requires only about 30 kilobytes ( $1 / 16$ of the original data). Therefore, to create a data archive, it is economical and desirable to archive partial data files rather than the entire original data file.

The above examples and result verification suggest that this procedure can be used in many remote-sensing applications, such as hydrological and meteorological studies. The procedure is simple and requires little execution time and effort. This program is MS-DOS compatible, and it can be run on most of the other microcomputers as well. It is notable that this program can work independently without WEFAX image receiving system if the WEFAX data is available.

ACKNOWLEDGMENTS: This study is performed under Japan-Bangladesh Joint Research Program by two governments. The authors would like to thank JICA (Japan International Cooperation Agency), BUET (Bangladesh University of Engineering and Technology), Ministry of Education, Japan, and Ministry of Foreign Affairs, Japan for their kind involvement in this project. The authors are also grateful to the Kajima Construction Co., NHK Enterprise, and Hitachi Techno Engineering for their financial supports in this project.

NOTE : This software was already handed to BUET in 1996, successfully being used in Bangladesh. Users interested in areas other than Bangladesh may contact to the authors, and the copies of the program may be obtained free of charge by sending a stamped self-addressed envelope to the authors' address.

\section{REFERENCE}

1) Bachmann M. and Bendix J. (1992) : An improved algorithm for NOAA-AVHRR image referencing, Int. J. Remote Sensing, 13, 16, pp. 3205-3215.

2) Chang Y. and Takagi M., (1995): A 
method for geometric correction of AVHRR data,日本リモートセンシング学会誌，15，1, pp. 16-39.

3) Cracknell A.P., and Paithoonwattanakij k. (1989) : Pixel and sub-pixel accuracy in geometrical correction of AVHRR imagery, Int. J. Remote Serising, 10, pp. 661667.

4) Emery W.J., Brown J. and Nowak Z.P. (1989) : AVHRR image navigation: summary and review, Photogrammetric engineering and remote sensing, 55, 8, pp. 1175
$-1183$.

5) Ho D. and Asem A. (1986) : NOAA AVHRR image referencing, Int. J. Remote Sensing, 7, 7, pp. 895-904.

6 ）静止気象衛星「ひまわり」画像受信システム, Weather sensor model 200 II (1992): Kenwood core corporation, Japan.

7 ）静止気象衛星「ひまわり」画像受信システム, GMSP-2 , ver3.0 (1993): Nippon Hakuyo Electronocs, ltd., Japan.

(Received: Feb. 12, 1997, Accepted: Feb. 26, 1997) 